\title{
Smoking and risk of ovarian cancer by histological subtypes: an analysis among 300000 Norwegian women
}

\author{
Idlir Licaj ${ }^{\star}, 1$, Bjarne Koster Jacobsen ${ }^{1}$, Randi Marie Selmer ${ }^{2}$, Gertraud Maskarinec ${ }^{3}$, Elisabete Weiderpass ${ }^{1,4,5,6}$ \\ and Inger Torhild Gram ${ }^{1}$ \\ ${ }^{1}$ Department of Community Medicine, Faculty of Health Sciences, The UiT Arctic University of Norway, Tromsø, Norway; \\ ${ }^{2}$ Norwegian Institute of Public Health, Oslo, Norway; ${ }^{3}$ University of Hawaii Cancer Center, Honolulu, HI, USA; ${ }^{4}$ Department of \\ Medical Epidemiology and Biostatistics, Karolinska Institutet, Stockholm, Sweden; ${ }^{5}$ Department of Research, Cancer Registry of \\ Norway, Institute of Population-Based Cancer Research, Oslo, Norway and ${ }^{6}$ Genetic Epidemiology Group, Folkhälsan Research \\ Center, Helsinki, Finland
}

Background: We prospectively investigated the association between different measures of smoking exposure and the risk of serous, mucinous, and endometrioid ovarian cancers (OC) in a cohort of more than 300000 Norwegian women.

Methods: We followed 300398 women aged 19-67 years at enrolment until 31 December 2013 for OC incidence through linkage to national registries. We used Cox proportional hazards models with attained age as the underlying time scale to estimate multivariable-adjusted hazard ratios (HRs) with 95\% confidence intervals (Cls) adjusted for relevant confounders.

Results: During more than 5.9 million person-years and a median follow-up time of 19 years, 2336 primary invasive $(1647,71 \%)$ and borderline $(689,29 \%)$ OC were identified (53\% serous, $19 \%$ mucinous). Compared with never smokers, current smokers who had smoked for $\geqslant 10$ years had a higher risk of mucinous $\mathrm{OC}\left(\mathrm{HR}_{10-19}\right.$ years vs never $=1.73,95 \% \mathrm{Cl} 1.24-2.42 ; \mathrm{HR} \geqslant 20$ vs never $=2.26,95 \% \mathrm{Cl}$ $\left.1.77-2.89, P_{\text {trend }}<0.001\right)$. When stratified by invasiveness, current smokers had a higher risk of invasive mucinous OC $(H R=1.78$, $95 \% \mathrm{Cl} 1.20-2.64)$ and borderline mucinous $\mathrm{OC}(\mathrm{HR}=2.2695 \% \mathrm{Cl}, 1.71-2.97)\left(P_{\text {heterogeneity }}=0.34\right)$ than never smokers. Smoking was not associated with serous or endometrioid OC.

Conclusions: Using a very large cohort of women, the current analysis provides an important replication for a similar risk of invasive and borderline mucinous OC related to smoking.

Cigarette smoking is an established risk factor for mucinous ovarian cancer (OC) with an estimated population attributable fraction of 14\% (Agudo et al, 2012; International Agency for Research on Cancer, 2012). Serous $(\approx 60 \%)$, mucinous $(\approx 10 \%)$, endometrioid, and clear cell (both $\approx 17 \%$ ) are the most common histological subtypes of OC (Kurman et al, 2014). The relationship between smoking and endometrioid and clear cell OC remains a controversial topic (Beral et al, 2012; Faber et al, 2013), as results are not consistent among studies (Terry et al, 2003). A recent pooled analysis included 51 epidemiological studies and found a
$79 \%$ increased risk of mucinous OC when comparing participants who were current and never smokers at study enrolment. This increased risk was driven by borderline malignant mucinous OC rather than invasive mucinous tumours (Beral et al, 2012). The authors found reduced risks of both endometrioid and clear cell OC, and no association for serous OC, in current smokers. The pooled analysis did not study the association between OC other measures of smoking exposure, such as number of cigarettes smoked per day, smoking duration, pack-years smoked or age at smoking initiation, and histological subtypes of OC.

*Correspondence: Dr I Licaj; E-mail: idlir.licaj@uit.no 
Moreover, few prospective studies have investigated the association between these measures of smoking exposure and histological subtypes of OC (Gram et al, 2008; Tworoger et al, 2008; Gram et al, 2012; Licaj et al, 2016; Wentzensen et al, 2016), and the results of the prospective studies are inconsistent. None of them found an association between mucinous OC and smoking duration, and only one (Gram et al, 2012) reported that mucinous OC was associated with the number of cigarettes smoked per day. In a recent study (Wentzensen et al, 2016), number of pack-years, which was the only measure of smoking exposure studied, was associated with a higher risk of invasive mucinous OC among ever smokers. Two reports from the same study population found a positive association between number of cigarettes smoked per day, smoking duration in years, and the risk of borderline OC (Gram et al, 2008; Licaj et al, 2016). One reason for the variation in these results may be the different methods employed to assess and analyse these measures of smoking exposure.

Thus, there is a need for large prospective studies on the relationship between smoking and the risk of OC. On the basis of a cohort of a more than 300000 Norwegian women, the purpose of this study was to investigate the role of smoking, including different measures of smoking exposure, in the risk of different histological subtypes of OC.

\section{MATERIALS AND METHODS}

Study population. The study population has been described previously (Næss et al, 2008; Bjerkaas et al, 2013). Briefly, it comprises Norwegian women recruited into different prospective cohort studies conducted by the Norwegian Institute of Public Health: the Norwegian Counties Study (1974-1988), the 40 Years Study (1985-1999), and the Cohort of Norway (CONOR) Study (1994-2003). All these cohorts are part of the Norwegian Health Screening Surveys. The response rate in the three studies ranged from 56 to 88\% (Stocks et al, 2010). Overall, 330342 women were eligible and 300398 remained in the analytical cohort after exclusions due to missing vital status $(n=95)$, prevalent cancer excluding non-melanoma skin cancer $(n=7180)$, emigration or death prior to study enrolment, and with inconsistencies in immigration and/or emigration dates $(n=3264)$. We further excluded women with missing information on smoking status $(n=2811)$ and other main covariates included in the analyses $(n=16594)$. The present study was approved by the Regional Committee for Medical Research Ethics South-East, Norway.

Data collection. Smoking status was defined at cohort entry as never, former, current, or ever smoker. The smoking questions were similar, across all three cohorts. The questionnaires collected information on current and former daily smoking habits, smoking duration, and average number of cigarettes smoked per day. Only the CONOR Study asked about age at smoking initiation. Thus, in the other surveys, we calculated this variable for both current (age at enrolment minus smoking duration in years) and former (age at enrolment minus years since quitting and smoking duration in years) smokers.

Information on number of children, age at first childbirth, and leisure time physical activity was also obtained from the questionnaires. Number of children was categorised into four groups $(0,1,2$, and $\geqslant 3)$, as was age at first childbirth $(<20,20-24$, $25-29$, and $\geqslant 30$ years). Physical activity was categorised into three groups: low (reading, watching television, and sedentary activity), moderate (walking, bicycling, or similar activities $\geqslant 4 \mathrm{~h}$ per week), and heavy (light sports or heavy gardening $\geqslant 4 \mathrm{~h}$ per week, heavy exercise or daily competitive sports). The most recent information regarding education was obtained from Statistics Norway and used to assign participants to one of the three categories: low
( $<10$ years), moderate (10-12 years), and high ( $>12$ years). Height and weight were measured at enrolment by a trained nurse and used to calculate body mass index (BMI), which was categorised as $\left(<25,25-29\right.$, and $\left.\geqslant 30 \mathrm{~kg} \mathrm{~m}^{-2}\right)$.

Information on menopausal status was available from questionnaires. For women with missing age at menopause, 50 years of age was used as a proxy measure of menopausal status.

Participants were followed for cancer incidence through record linkage with the Cancer Registry of Norway, and for death and emigration through linkage to the Norwegian Central Population Register. These national registries contain correct, detailed, virtually complete information on cancer incidence and mortality (Larsen et al, 2009). The International Classification of Diseases (ICD-7 code 175 or corresponding ICD-9 or ICD-10 codes) and the World Health Organization's International Histological Classification of Tumours were used to identify four histological subtypes of OC (serous, mucinous, endometrioid, and clear cell) and to determine invasiveness (borderline and invasive). However, due to a small number of cases, we chose not to show results for clear cell OC.

Statistical analysis. Cox proportional hazards models with attained age as the underlying time scale were used to estimate multivariable-adjusted hazard ratios (HRs) with 95\% confidence intervals (CI) for the associations between smoking status and OC overall, for the three histological subtypes we investigated (serous, mucinous, endometrioid), and for invasiveness of OCs. We then carried out the same analyses after reclassifying ever smokers according to different measures of exposure: duration $(<10$, $10-19, \geqslant 20$ years, and missing $n=1795)$, number of pack-years $(<6,6-15, \geqslant 16$, and missing $n=2707)$, number of cigarettes smoked per day $(<6,6-15, \geqslant 16$, and missing $n=1587)$, and age at smoking initiation $(<20,20-24, \geqslant 25$ years, and missing $n=34397$ ). For the these analyses, we included missing indicators after checking that the parameters associated with these indicators were not statistically significantly associated with risk of OC overall or by histological subtype. Never smokers were used as the reference group. The start of the follow-up was defined as age at enrolment, and exit time as age at any incident cancer diagnosis (including OC) (except basal cell carcinoma), emigration, death, or the end of follow-up (31 December 2013), whichever occurred first.

Similar models were used to estimate multivariable-adjusted HRs with 95\% CIs for the association between different measures of smoking exposure and serous and mucinous OC stratified by invasiveness. We were not able to do this for endometrioid and clear cell OC due to small numbers.

Wald $\chi^{2}$ statistics were used to test for heterogeneity between histological subtypes. Models were stratified by cohort study and birth cohort ( $\leqslant 1950$ and $>1950$ ). If a linear trend was observed for a specific measure of smoking exposure, that exposure was also tested as a continuous variable.

Analysis were adjusted for available established risk factors for OC (World Cancer Research Fund \& American Institute for Cancer Research, 2014). In order to be retained in the final model, the removal of the covariate had to lead to a change in the regression coefficients of at least $10 \%$ in any of the smoking status groups. The final model included the covariates: number of children, age at first childbirth, physical activity level, and BMI.

We did not include use of hormone therapy (information available for $n=89637$ ) or oral contraceptives (information available for $n=80736$ ) in the main analyses as this information was only available in the 40 Years Study and the CONOR Study. Instead, we performed sensitivity analyses in these cohorts that included these two covariates. Tests for trend across categories of measures of smoking exposure were based on the median value in each category and included never smokers. We created separate models that included and excluded never smokers. 
We tested if the proportional hazard assumption was met using Schoenfeld residuals. The modifying effect of number of children, education, physical activity, BMI, and menopausal status on the relationship between smoking status and OC was also assessed. Models with main effects and interaction terms were fitted and compared with models with only main effects. The difference in log-likelihood (likelihood ratio test statistics) was compared with a $\chi^{2}$ distribution with degrees of freedom equal to the number of interaction terms.

All analyses were performed in STATA version 14.0 (StataCorp, College Station, TX, USA) and in SAS version 9.4 (SAS Institute Inc., Cary, NC, USA).

\section{RESULTS}

Median age at cohort entrance was 41 years. During more than 5.9 million person-years and a median follow-up of 19 years, 2336 cases of primary OC were identified. There were 1242 (53\%) serous OC, 440 (19\%) mucinous OC, 190 (8\%) endometrioid OC, and 82 (4\%) clear cell OC. Altogether 1647 (71\%) were diagnosed with invasive and 689 (29\%) with borderline tumours. In this study 38\% of women were current, $21 \%$ former, and $41 \%$ never smokers at enrolment. Current smokers had an earlier age at first childbirth, more often reported low physical activity, had less years of education when compared with never smokers (Table 1).

When compared with women with serous OC, those with mucinous OC had an older age at first childbirth, more often reported low physical activity and were more often overweight $\left(\mathrm{BMI} \geqslant 25 \mathrm{~kg} / \mathrm{m}^{2}\right)$. Borderline OC was more often seen in obese
$\left(\mathrm{BMI} \geqslant 30 \mathrm{~kg} / \mathrm{m}^{2}\right)$ and nulliparous women when compared with women with invasive OC (Supplementary Table 1).

Current smokers had a higher risk of all borderline OC but smoking was not associated with all invasive, serous, or endometrioid OC (Table 2). No increased risk of mucinous OC was observed for former smokers, whereas current smokers had a more than two-fold higher risk $(\mathrm{HR}=2.09,95 \%$ CI $1.67-2.62)$ when compared with never smokers. The elevated risk of mucinous OC was somewhat lower in ever smokers $(\mathrm{HR}=1.70,95 \% \mathrm{CI}$ 1.37-2.10). Compared with never smokers, current smokers who had smoked for 10-19 years had a higher risk of mucinous OC $(\mathrm{HR}=1.73,95 \%$ CI $1.24-2.42)$ as did those who smoked for more than 20 years $\left(\mathrm{HR}=2.26,95 \% \mathrm{CI} 1.77-2.89 ; P_{\text {linear trend }}<0.001\right)$. We observed a higher risk of mucinous OC among current smokers who smoked 6-15 pack-years $(\mathrm{HR}=2.44$, 95\% CI 1.90 $3.14)$, those who smoked more than 16 pack-years $(\mathrm{HR}=1.95$, 95\% CI 1.41-2.70), those who smoked 6-15 cigarettes per day $(\mathrm{HR}=2.18,95 \% \mathrm{CI} 1.71-2.77)$, and those who smoked more than 16 cigarettes per day $(\mathrm{HR}=2.46,95 \% \mathrm{CI} 1.73-3.50)$. The risk of mucinous OC was similar among current smokers who started smoking before 19 years of age $(\mathrm{HR}=2.12,95 \% \mathrm{CI} 1.65-2.72)$ and those who started after 20 years of age $(\mathrm{HR}=1.73,95 \%$ CI 1.24 2.42). For current smokers, we observed a positive trend between smoking duration, number of pack-years, number of cigarettes smoked per day, and age at smoking initiation and the risk of mucinous OC and all borderline OCs (Table 2). We observed similar trends with and without never smokers. We found that each additional year of cigarette smoking increased the risk of mucinous OCs by $2 \%$. The same elevated risk was found for each additional cigarette smoked per day.

Table 1. Baseline characteristics of the analytical sample according smoking status, Norwegian women, $N=300398$ (1974-2013)

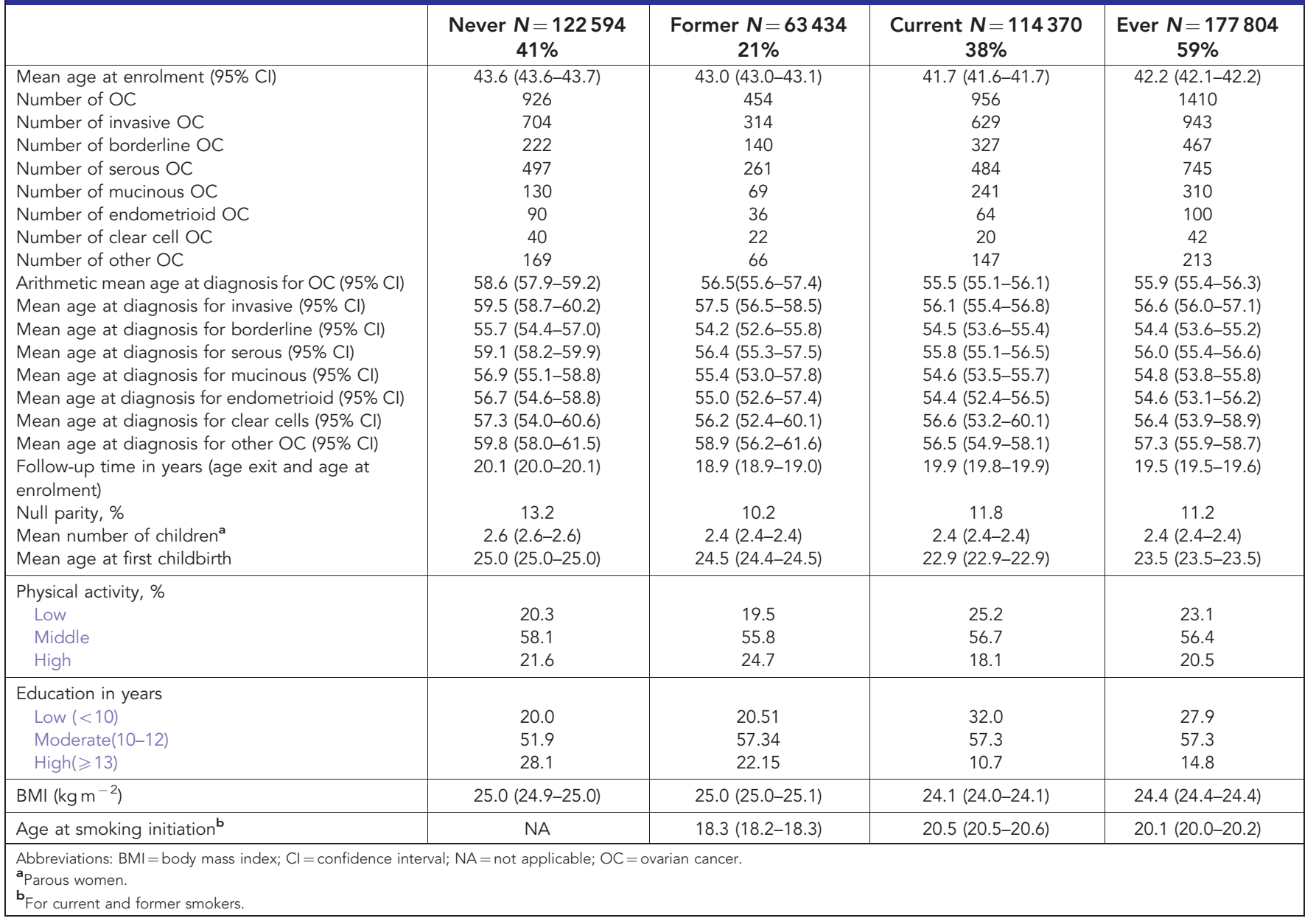


Table 2. Multivariable ${ }^{a}$ HRs $(95 \% \mathrm{Cl})$ of invasiveness status and by histological subtypes according of OCs according to various measures of smoking status compared with never smokers 300398 Norwegian women

\begin{tabular}{|c|c|c|c|c|c|c|c|c|c|c|}
\hline & \multicolumn{2}{|c|}{ All borderline ${ }^{b}$} & \multicolumn{2}{|c|}{ All invasive ${ }^{b}$} & \multicolumn{2}{|r|}{ Serous $^{c}$} & \multicolumn{2}{|c|}{ Mucinous $^{c}$} & \multicolumn{2}{|c|}{ Endometrioid $^{c}$} \\
\hline & $n_{\text {cases }}$ & HR (95\% Cl) & $n_{\text {cases }}$ & HR $(95 \% \mathrm{Cl})$ & $n_{\text {cases }}$ & HR (95\% Cl) & $n_{\text {cases }}$ & HR (95\% Cl) & $\mathbf{n}_{\text {cases }}$ & HR $(95 \% \mathrm{Cl})$ \\
\hline \multicolumn{11}{|c|}{ Smoking status } \\
\hline Never & 222 & & 704 & 1.00 & 497 & 1.00 & 130 & 1.00 & 90 & 1.00 \\
\hline Former & 140 & $1.23(0.99-1.52)$ & 314 & $95(0.83-1.08)$ & 261 & $.03(0.88-1.20)$ & 69 & $1.09(0.81-1.47)$ & 36 & $0.83(0.56-1.23)$ \\
\hline Current & 327 & $1.55(1.29-1.85)$ & 629 & $0.97(0.86-1.08)$ & 484 & $0.99(0.87-1.13)$ & 241 & $2.09(1.67-2.62)$ & 64 & $0.74(0.53-1.03)$ \\
\hline Ever & 467 & $1.42(1.20-1.68)$ & 943 & $0.96(0.87-1.06)$ & 745 & $1.00(0.89-1.13)$ & 310 & $1.70(1.37-2.10)$ & 100 & $0.77(0.57-1.04)$ \\
\hline
\end{tabular}

Smoking duration in years

\begin{tabular}{|c|c|c|c|c|c|c|c|c|c|c|}
\hline $\begin{array}{c}\text { Former } \\
<9\end{array}$ & 56 & $123(091-165)$ & 98 & 095 (078-1 15) & 98 & 090 & 26 & $105(068-160)$ & 15 & $087(050-150)$ \\
\hline $10-19$ & 56 & $1.18(0.87-1.58)$ & 108 & $0.96(0.80-1.16)$ & 108 & $1.04(0.84-1.28)$ & 28 & $1.07(0.71-1.62)$ & 19 & $1.06(0.64-1.74)$ \\
\hline $\begin{array}{l}20+ \\
P_{\text {trend }} \mathrm{d}\end{array}$ & 25 & $\begin{array}{c}1.25(0.82-1.91) \\
0.07\end{array}$ & 51 & $\begin{array}{c}0.89(0.68-1.18) \\
0.53\end{array}$ & 51 & $\begin{array}{c}1.13(0.84-1.52) \\
0.47\end{array}$ & 13 & $\begin{array}{c}1.12(0.63-2.00) \\
0.04\end{array}$ & 2 & $\begin{array}{c}0.28(0.07-1.14) \\
0.18\end{array}$ \\
\hline Current & & & & & & & & & & \\
\hline $\begin{array}{l}\leqslant 9 \\
10-19\end{array}$ & 18 & $\begin{array}{l}1.25(0.74-2.09) \\
1.27\end{array}$ & $\begin{array}{l}28 \\
96\end{array}$ & $\begin{array}{l}0.91(0.65-1.28) \\
0.87(0.72-1.05)\end{array}$ & $\begin{array}{l}28 \\
96\end{array}$ & $0.95(0.64-1.42)$ & $\begin{array}{l}13 \\
51\end{array}$ & $\begin{array}{l}1.64(0.90-2.98) \\
173(124-2.42)\end{array}$ & 6 & $1.01(0.42-2.45)$ \\
\hline $\begin{array}{l}20+ \\
P_{\text {trend }} \mathbf{d}\end{array}$ & 243 & $\begin{array}{l}1.68(1.38-2.04) \\
<0.001\end{array}$ & 359 & $\begin{array}{c}1.02(0.90-1.16) \\
0.75\end{array}$ & 359 & $\begin{array}{c}1.04(0.90-1.21) \\
0.24\end{array}$ & 175 & $\begin{array}{l}2.26(1.77-2.89) \\
\quad<0.001\end{array}$ & 47 & $\begin{array}{c}0.84(0.57-1.23) \\
0.11\end{array}$ \\
\hline \multicolumn{11}{|c|}{ Pack-years } \\
\hline $\begin{array}{c}\text { Former } \\
\leqslant 5\end{array}$ & 76 & $1.15(0.88-1.49)$ & 153 & $0.98(0.83-1.15)$ & 153 & $1.05(0.87-1.26)$ & 36 & $0.98(0.67-1.42)$ & 20 & $0.79(0.48-1.28)$ \\
\hline $6-15$ & 44 & $1.22(0.88-1.69)$ & 68 & $0.84(0.67-1.05)$ & 68 & $0.86(0.67-1.11)$ & 24 & $1.21(0.78-1.88)$ & 15 & $1.11(0.64-1.93)$ \\
\hline $\begin{array}{l}16+ \\
P_{\text {trend }} \mathrm{d}\end{array}$ & 15 & $\begin{array}{c}1.60(0.94-2.72) \\
0.025\end{array}$ & 33 & $\begin{array}{c}1.11(0.76-1.62) \\
0.61\end{array}$ & 33 & $\begin{array}{c}1.64(1.14-2.34) \\
0.89\end{array}$ & 5 & $\begin{array}{c}0.97(0.39-2.39) \\
0.13\end{array}$ & 1 & $\begin{array}{c}0.31(0.04-2.24) \\
0.28\end{array}$ \\
\hline $\begin{array}{c}\text { Current } \\
\leqslant 5\end{array}$ & 48 & $1.17(0.85-1.62)$ & 86 & $0.86(0.70-1.05)$ & 86 & $0.96(0.76-1.22)$ & 32 & $1.37(0.92-2.04)$ & 9 & $0.52(0.26-1.06)$ \\
\hline $6-15$ & 165 & $1.51(1.22-1.86)$ & 237 & $1.03(0.90-1.18)$ & 237 & $0.92(0.78-1.08)$ & 147 & $2.44(1.90-3.14)$ & 36 & $0.83(0.55-1.24)$ \\
\hline $\begin{array}{l}16+ \\
P_{\text {trend }} \mathbf{d}\end{array}$ & 111 & $\begin{array}{l}1.90(1.49-2.43) \\
\quad<0.001\end{array}$ & 159 & $\begin{array}{c}0.96(0.80-1.15) \\
0.50\end{array}$ & 159 & $\begin{array}{c}1.15(0.95-1.39) \\
0.84\end{array}$ & 60 & $\begin{array}{l}1.95(1.41-2.70) \\
\quad<0.001\end{array}$ & 19 & $\begin{array}{c}0.88(0.52-1.48) \\
0.29\end{array}$ \\
\hline
\end{tabular}

\section{Number of cigarettes per day}

\begin{tabular}{|c|c|c|c|c|c|c|c|c|c|c|}
\hline $\begin{array}{l}\text { Former } \\
\leqslant 5\end{array}$ & 41 & $1.31(0.94-1.83)$ & 74 & $0.97(0.78-1.20)$ & 74 & $1.06(0.83-1.36)$ & 17 & 0.95 (0.57-1.59) & 13 & $1.1(0.61-1.98)$ \\
\hline $6-15$ & 73 & $1.10(0.84-1.43)$ & 136 & $0.92(0.78-1.09)$ & 136 & $0.93(0.77-1.13)$ & 43 & $1.19(0.84-1.69)$ & 17 & $0.67(0.4-1.14)$ \\
\hline $\begin{array}{l}16+ \\
P_{\text {trend }} \mathrm{d}\end{array}$ & 23 & $\begin{array}{c}1.53(0.99-2.36) \\
0.08\end{array}$ & 45 & $\begin{array}{c}1.03(0.75-1.42) \\
0.68\end{array}$ & 45 & $\begin{array}{c}1.43(1.05-1.95) \\
0.29\end{array}$ & 8 & $\begin{array}{c}1.02(0.50-2.10) \\
0.98\end{array}$ & 6 & $\begin{array}{c}1.11(0.48-2.55) \\
0.25\end{array}$ \\
\hline $\begin{array}{c}\text { Current } \\
\leqslant 5\end{array}$ & 31 & $1.21(0.83-1.77)$ & 52 & $0.80(0.62-1.03)$ & 52 & $0.89(0.67-1.19)$ & 21 & $1.44(0.91-2.29)$ & 4 & $0.38(0.14-1.05)$ \\
\hline $6-15$ & 221 & $1.49(1.22-1.81)$ & 342 & $1.02(0.90-1.16)$ & 342 & $0.99(0.85-1.14)$ & 175 & $2.18(1.71-2.77)$ & 48 & $0.82(0.57-1.19)$ \\
\hline $\begin{array}{l}16+ \\
P_{\text {trend }} \mathrm{d}\end{array}$ & 73 & $\begin{array}{l}2.02(1.53-2.67) \\
\quad<0.001\end{array}$ & 88 & $\begin{array}{c}0.94(0.75-1.17) \\
0.66\end{array}$ & 88 & $\begin{array}{c}1.05(0.83-1.33) \\
0.81\end{array}$ & 46 & $\begin{array}{l}2.46(1.73-3.50) \\
\quad<0.001\end{array}$ & 12 & $\begin{array}{c}0.89(0.48-1.65) \\
0.28\end{array}$ \\
\hline
\end{tabular}

\section{Age at smoking initiation}

\begin{tabular}{|c|c|c|c|c|c|c|c|c|c|c|}
\hline \multicolumn{11}{|l|}{ Former } \\
\hline $20+$ & 14 & $1.03(0.58-1.83)$ & 34 & $1.16(0.80-1.68)$ & 34 & $1.42(0.97-2.08)$ & 5 & $0.61(0.24-1.54)$ & 3 & $1.10(0.32-3.80)$ \\
\hline$\leqslant 19$ & 37 & $1.11(0.75-1.66)$ & 67 & 1.19 (0.89-1.59) & 67 & $1.18(0.87-1.59)$ & 20 & $1.30(0.75-2.25)$ & 8 & $1.08(0.46-2.54)$ \\
\hline$P_{\text {trend }}{ }^{\mathbf{d}}$ & & 0.04 & & 0.12 & & 0.69 & & 0.51 & & 0.28 \\
\hline \multicolumn{11}{|l|}{ Current } \\
\hline $20+$ & 163 & $1.48(1.20-1.82)$ & 237 & 0.95 (0.84-1.09) & 237 & $0.90(0.77-1.06)$ & 136 & $2.12(1.65-2.72)$ & 34 & $0.72(0.48-1.09)$ \\
\hline$\leqslant 19$ & 163 & $1.63(1.30-2.03)$ & 246 & $1.01(0.86-1.17)$ & 246 & $1.11(0.94-1.32)$ & 105 & $2.03(1.53-2.69)$ & 30 & $0.84(0.54-1.33)$ \\
\hline$P_{\text {trend }}{ }^{\mathbf{d}}$ & & $<0.001$ & & 0.51 & & 0.57 & & $<0.001$ & & 0.23 \\
\hline
\end{tabular}

Abbreviations: $\mathrm{BMI}=$ body mass index; $\mathrm{Cl}=$ confidence interval; $\mathrm{HR}=$ hazard ratios; $\mathrm{OC}=$ ovarian cancer

${ }^{a}$ Adjusted for number of children $(0,1,2$, and $\geqslant 3)$, age at first childbirth $\left(<20,20-24,25-29\right.$, and $\geqslant 30$ years), BMI $\left(<25,25-29\right.$, and $\geqslant 30$ kg m $\left.{ }^{-2}\right)$, and level of physical activity (low, moderate, and heavy).

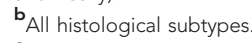

Include invasive and borderline tumours.

$\mathrm{d}_{\text {Trend tests include never smokers. }}$

When we stratified serous and mucinous OC by invasiveness (Table 3), current compared with never smokers were at higher risk of invasive mucinous $\mathrm{OC}(\mathrm{HR}=1.78,95 \% \mathrm{CI} 1.20-2.64)$ and of borderline mucinous OC $(\mathrm{HR}=2.26,95 \%$ CI $1.71-2.97)$. The test for heterogeneity showed that there was no difference between invasive and borderline mucinous OC $\left(P_{\text {heterogeneity }}=0.34\right)$. We observed a positive trend between smoking duration and risk of invasive and borderline mucinous OC, but not for borderline serous or invasive serous OC (Table 3). The risk for all histological subtypes of OC was similar in former and never smokers.
We combined three smoking characteristics age at smoking initiation, duration, and cigarettes smoked per day (Table 4). In women who smoked for more than 10 years and more than 10 cigarettes per day, the age at smoking initiation ( $<18$ years or older) had little impact on the risk of mucinous OC when compared with never smokers. They were $\mathrm{HR}=1.77$ (95\% CI 1.26-2.49) and $\mathrm{HR}=2.42$ (95\% CI 1.88-3.10), respectively (Table 4).

We found no statistically significant interactions between smoking status and number of children, physical activity, education, or BMI in relation to mucinous or other histological 
Table 3. Multivariable ${ }^{a} \mathrm{HR}(95 \% \mathrm{Cl})$ of serous and mucinous epithelial OC overall by invasive status according to various measures of smoking status at enrolment compared with never smokers in 300398 Norwegian women

\begin{tabular}{|c|c|c|c|c|c|c|c|c|}
\hline OCs & $N_{\text {cases }}$ & $\begin{array}{l}\text { Invasive mucinous } \\
\qquad N=138\end{array}$ & $N_{\text {cases }}$ & $\begin{array}{l}\text { Borderline mucinous } \\
\qquad N=302\end{array}$ & $N_{\text {cases }}$ & $\begin{array}{l}\text { Invasive serous } \\
\qquad N=888\end{array}$ & $N_{\text {cases }}$ & $\begin{array}{c}\text { Borderline serous } \\
\qquad N=354\end{array}$ \\
\hline \multicolumn{9}{|c|}{ Smoking status } \\
\hline Never & 45 & 1.00 & 85 & 1.00 & 371 & 1.00 & 126 & 1.00 \\
\hline Former & 21 & $1.01(0.60-1.70)$ & 48 & $1.14(0.80-1.63)$ & 175 & $0.94(0.79-1.13)$ & 86 & $1.27(0.96-1.67)$ \\
\hline Current & 72 & $1.78(1.20-2.64)$ & 169 & $2.26(1.71-2.97)$ & 342 & $0.94(0.81-1.10)$ & 142 & $1.11(0.86-1.43)$ \\
\hline Ever & 93 & $1.49(1.03-2.16)$ & 217 & $1.81(1.40-2.35)$ & 517 & $0.94(0.82-1.08)$ & 228 & $1.17(0.93-1.47)$ \\
\hline
\end{tabular}

Smoking duration in years

\begin{tabular}{l|r|c|c|r|r|r|r|r}
\hline Ever smokers & & & & & & \\
$\leqslant 9$ & 7 & $0.65(0.29-1.44)$ & 32 & $1.42(0.94-2.15)$ & 88 & $0.95(0.75-1.20)$ & 38 \\
$10-19$ & 27 & $1.42(0.88-2.31)$ & 52 & $1.42(1.00-2.01)$ & 143 & $0.90(0.74-1.09)$ & 61 \\
$20+$ & 58 & $1.89(1.25-2.86)$ & 130 & $2.25(1.68-3.01)$ & 283 & $0.97(0.83-1.15)$ & $1.07(0.79-1.47)$ \\
$P_{\text {trend }}$ & & 0.001 & & $<0.001$ & $1.60)$ \\
\hline
\end{tabular}

Pack-years

\begin{tabular}{|l|c|c|c|c|c|c|c|c|}
\hline Ever smokers & & & & & & & & \\
$\leqslant 5$ & 19 & $0.94(0.55-1.61)$ & 49 & $1.22(0.85-1.74)$ & 169 & $0.98(0.81-1.18)$ & 70 & $1.14(0.85-1.53)$ \\
$6-15$ & 55 & $1.96(1.30-2.96)$ & 116 & $2.20(1.65-2.95)$ & 225 & $0.90(0.76-1.07)$ & 80 & $0.92(0.69-1.22)$ \\
$16+$ & 17 & $1.37(0.77-2.46)$ & 48 & $2.05(1.41-2.96)$ & 118 & $1.00(0.80-1.24)$ & 74 & $1.76(1.30-2.38)$ \\
$P_{\text {trend }}$ & & 0.07 & & 0.01 & & 0.35 & 0.01 \\
\hline
\end{tabular}

Number of cigarettes per day

\begin{tabular}{|c|c|c|c|c|c|c|c|c|}
\hline \multicolumn{9}{|l|}{ Ever smokers } \\
\hline$\leqslant 5$ & 11 & $1.02(0.52-1.98)$ & 26 & $1.21(0.78-1.88)$ & 84 & $0.89(0.70-1.12)$ & 42 & $1.28(0.90-1.83)$ \\
\hline $6-15$ & 67 & $1.68(1.13-2.49)$ & 151 & $1.93(1.46-2.54)$ & 349 & $0.96(0.82-1.12)$ & 129 & $1.00(0.77-1.29)$ \\
\hline $\begin{array}{l}16+ \\
P_{\text {trend }}\end{array}$ & 15 & $\begin{array}{c}1.68(0.92-3.08) \\
0.008\end{array}$ & 39 & $\begin{array}{c}2.18(1.48-3.23) \\
<0.001\end{array}$ & 80 & $\begin{array}{c}0.95(0.74-1.22) \\
0.60\end{array}$ & 53 & $\begin{array}{c}1.66(1.19-2.31) \\
0.02\end{array}$ \\
\hline
\end{tabular}

Age at smoking initiation

\begin{tabular}{|l|l|l|l|l|r|r|r|r}
\hline Ever smokers & & & & & & \\
$25+$ & 14 & $1.36(0.74-2.48)$ & 28 & $1.61(1.05-2.48)$ & 78 & $0.94(0.74-1.21)$ & 24 \\
$20-24$ & 32 & $2.02(1.27-3.23)$ & 67 & $2.33(1.68-3.23)$ & 120 & $0.88(0.71-1.08)$ & 49 \\
$<20$ & 32 & $1.61(0.98-2.64)$ & 93 & $2.12(1.53-2.92)$ & 213 & $1.06(0.88-1.28)$ & 100 \\
$P_{\text {trend }}$ & & 0.97 & 0.04 & $1.19(0.89-1.47)$ \\
\hline
\end{tabular}

Abbreviations: $\mathrm{BMI}=$ body mass index; $\mathrm{Cl}=$ confidence interval; $\mathrm{HR}=$ hazard ratios; $\mathrm{OC}=$ ovarian cancer.

${ }^{a}$ Adjusted for number of children $(0,1,2$, and $\geqslant 3)$, age at first childbirth $(<20,20-24,25-29$, and $\geqslant 30$ years), BMl $(<25,25-29$, and $\geqslant 30 \mathrm{~kg} / \mathrm{m} 2)$, and level of physical activity (sedentary, moderate, and heavy).

Table 4. Multivariable ${ }^{\mathrm{a}}$ hazard ratios $\left(95 \%\right.$ confidence interval) of three combined smoking characteristics ${ }^{\mathrm{b}}$ (duration in years, number of cigarettes per day and age at start) and serous mucinous and endometrioid tumours in 300398 Norwegian women

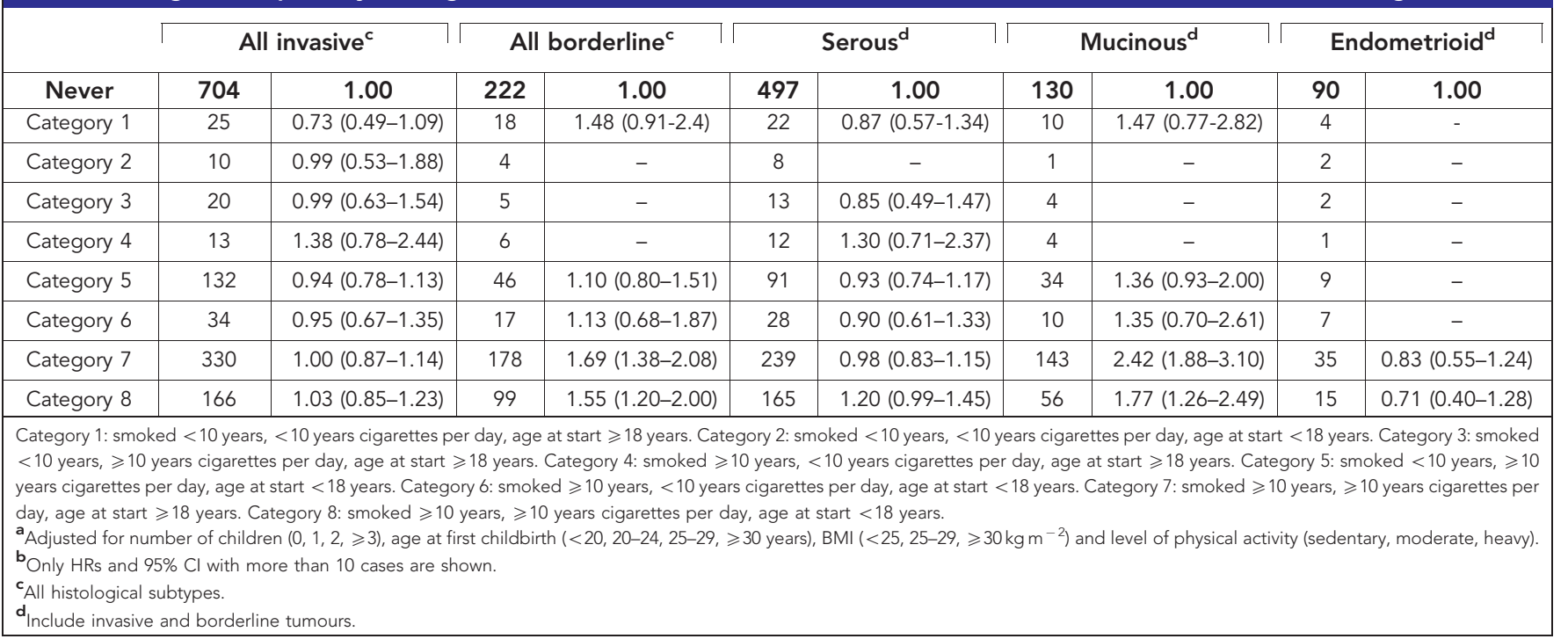

subtypes of OC. We observed similar higher risks of mucinous OC when current smokers were compared with never smokers in analyses stratified by BMI $\left(<25 \mathrm{~kg} \mathrm{~m}^{-2}: \mathrm{HR}=2.36,95 \%\right.$ CI $1.74-$
3.19; $25-29 \mathrm{~kg} \mathrm{~m}^{-2}: \mathrm{HR}=1.62,95 \%$ CI $1.07-2.44 ; \geqslant 30 \mathrm{~kg} \mathrm{~m}^{-2}$ : $\mathrm{HR}=2.20$, 95\% CI 1.17-4.13), but also when stratified by physical activity and number of children (data not shown). 
We observed no differences in sensitivity analyses that were additionally adjusted for hormone therapy and oral contraceptive use (data not shown).

\section{DISCUSSION}

In this large, prospective study, cigarette smoking was associated with invasive and borderline mucinous OC, but not with other histological subtypes of OC. For invasive and borderline mucinous OC, we observed a significant, dose-response association with smoking duration, pack-years, and number of cigarettes smoked per day. When restricting the analyses to smokers, we found that each additional year of cigarette smoking and each increase of one cigarette per day increased the risk of mucinous OC by $2 \%$.

Our study complements the results from two recent pooled analyses of smoking and OC (Beral et al, 2012; Faber et al, 2013) that included 14724 and 28114 cases of OC, respectively. One was from a collaborative group on epidemiological studies of OC including both prospective cohorts and case-control studies and reported that borderline mucinous $(\mathrm{HR}=2.25,95 \% \mathrm{CI} 1.91-2.65)$ and invasive mucinous $(\mathrm{HR}=1.49,95 \%$ CI $1.28-1.73 ; P$ for heterogeneity 0.01) OC incidence were increased when current smokers were compared with never smokers. This collaborative study did not include dose-response associations for different measures of cigarette smoking or for subtypes of OC. The second pooled analysis studied dose-response associations with different measures of cigarette smoking, but only included case-control studies (Faber et al, 2013). Both studies reported lower smokingrelated risks of invasive mucinous OC among current smokers than we observed in our study. In contrast to the first pooled analysis of 51 epidemiological studies, our study demonstrated that smoking increased the risk of both invasive and borderline mucinous $\mathrm{OC}$ to a similar extent. In contrast to the pooled analysis of 21 case-controls studies (Faber et al, 2013), we did not find an association between cigarette smoking and risk of borderline serous OC.

The few prospective cohort studies that have investigated the association between measure of smoking exposure and the risk of subtypes of OC (Tworoger et al, 2008; Gram et al, 2012; Licaj et al, 2016) found no association between smoking duration and mucinous OCs. Each 20 additional pack-years in ever compared with never smokers was associated with a significant $20 \%$ higher risk of invasive mucinous OC (Wentzensen et al, 2016).

In our study, neither BMI nor education was revealed as an effect modifier for the association between smoking and histological subtypes of OC, as there was no evidence of statistically significant interaction.

Mucinous OC shares its histological appearance and its association with smoking with colorectal cancer (Newcomb et al, 1995; Parajuli et al, 2014). As a potential biological mechanism, somatic mutations in the KRAS gene are common in borderline tumours but not in invasive epithelial OC, and were found to be more frequent in borderline mucinous than in borderline serous OC (Mayr et al, 2006). Cigarette smoking was found to induce KRAS mutations in patients with lung, pancreatic, and colon cancers (Diergaarde et al, 2003; Jiao et al, 2007; Baykara et al, 2013). A similar mechanism of oncogenesis might be applicable to mucinous OC. Adducts of benzo(a)pyrene, a potent local carcinogen, have been found in ovarian follicular cells of women exposed to cigarette smoke (Zenzes et al, 1998). The DNAdamaging effect of adducts might partially explain a biological plausibility between smoking and mucinous ovarian cancer.

Strengths and limitations. The main strength of this study is the large number of enrolled women, representing all counties in Norway, the virtually complete long-term follow-up, the large number of OC overall, and of histological subtypes of OC. In our analysis, we stratified the analyses by two birth cohorts $(\leqslant 1950$ and $>1950$ ), as reproductive and lifestyle factors changed during follow-up.

The limitations include lack of complete information for established risk factors such as age at menopause and menarche, use of oral contraceptives and hormone therapy. The sensitivity analyses controlling for hormone therapy and oral contraceptive use cannot be representative of our entire sample and should be interpreted with caution. The use of HT became more widespread after 1990 (Bakken et al, 2004), and may be a more important limitation in younger birth cohorts than it is in our study. In the recent consortia study by Wentzensen et al (2016), ever use of oral contraceptive was associated with a lower risk of all invasive OC, whereas ever use of hormone therapy was associated with a higher risk; but none of these two factors was associated with invasive mucinous OC. When we additionally adjusted for hormone therapy and oral contraceptive in our sensitivity analyses, we observed similar results.

Another limitation of our study is the possible misclassification of histological subtypes of OC and invasiveness. We relied on pathology information recorded by local pathologists. We believe that a differential misclassification of OC subtypes between current/ former and never smokers is unlikely. In addition, we observe significant differences between subtype and invasiveness of OC, which is not supporting significant misclassification in our data.

The prevalence of smoking in Norway continuously decreased during the follow-up period of this study (1974-2013), but we had no updated information on smoking status for all participants. Comparison of OC risk between ever and never smokers gave similar results as the comparison between current and never smokers. As only never smokers could change their smoking status during follow-up (women who quit smoking will still be ever smokers), misclassification in smoking status in the follow-up period can be assumed to be low and there is little chance of misclassification bias, which would tend to attenuate the current findings. However, the long study period without follow-up information limits our ability to infer causality. Possible misclassification of histological types of OC and invasiveness may also be present, but we believe that differential misclassification of OC subtypes between current and never smokers is unlikely.

\section{CONCLUSION}

We found a dose-response association between smoking duration, pack-years, and number of cigarettes smoked per day, and both invasive and borderline mucinous OC. This large confirmation study add further evidence that smoking increases the risk of invasive and borderline mucinous OC to a similar extent.

\section{ACKNOWLEDGEMENTS}

This work was supported by grants from 'Norwegian Cancer Society'.

CONFLICT OF INTEREST

The authors declare no conflict of interest.

\section{REFERENCES}

Agudo A, Bonet C, Travier N, Gonzalez CA, Vineis P, Bueno-de-Mesquita HB, Trichopoulos D, Boffetta P, Clavel-Chapelon F, Boutron-Ruault MC, Kaaks R, Lukanova A, Schütze M, Boeing H, Tjonneland A, Halkjaer J, 
Overvad K, Dahm CC, Quirós JR, Sánchez MJ, Larrañaga N, Navarro C, Ardanaz E, Khaw KT, Wareham NJ, Key TJ, Allen NE, Trichopoulou A, Lagiou P, Palli D, Sieri S, Tumino R, Panico S, Boshuizen H, Büchner FL, Peeters PH, Borgquist S, Almquist M, Hallmans G, Johansson I, Gram IT, Lund E, Weiderpass E, Romieu I, Riboli E (2012) Impact of cigarette smoking on cancer risk in the European prospective investigation into cancer and nutrition study. J Clin Oncol 30(36): 4550-4557.

Bakken K, Alsaker E, Eggen AE, Lund E (2004) Hormone replacement therapy and incidence of hormone-dependent cancers in the Norwegian Women and Cancer study. Int J Cancer 112(1): 130-134.

Baykara O, Tansarikaya M, Demirkaya A, Kaynak K, Tanju S, Toker A, Buyru N (2013) Association of epidermal growth factor receptor and $\mathrm{K}$-Ras mutations with smoking history in non-small cell lung cancer patients. Exp Ther Med 5(2): 495-498.

Beral V, Gaitskell K, Hermon C, Moser K, Reeves G, Peto R (2012) Ovarian cancer and smoking: individual participant meta-analysis including 28114 women with ovarian cancer from 51 epidemiological studies. Lancet Oncol 13(9): 946-956.

Bjerkaas E, Parajuli R, Weiderpass E, Engeland A, Maskarinec G, Selmer R, Gram IT (2013) Smoking duration before first childbirth: an emerging risk factor for breast cancer? Results from 302,865 Norwegian women. Cancer Causes Control 24(7): 1347-1356.

Diergaarde B, Vrieling A, van Kraats AA, van Muijen GN, Kok FJ, Kampman E (2003) Cigarette smoking and genetic alterations in sporadic colon carcinomas. Carcinogenesis 24(3): 565-571.

Faber MT, Kjaer SK, Dehlendorff C, Chang-Claude J, Andersen KK, Hogdall E, Webb PM, Jordan SJ. Australian Cancer Study (Ovarian Cancer)Australian Ovarian Cancer Study GroupRossing MA, Doherty JA, Lurie G, Thompson PJ, Carney ME, Goodman MT, Ness RB, Modugno F, Edwards RP, Bunker CH, Goode EL, Fridley BL, Vierkant RA, Larson MC, Schildkraut J, Cramer DW, Terry KL, Vitonis AF, Bandera EV, Olson SH, King M, Chandran U, Kiemeney LA, Massuger LF, van Altena AM, Vermeulen SH, Brinton L, Wentzensen N, Lissowska J, Yang HP, Moysich KB, Odunsi K, Kasza K, Odunsi-Akanji O, Song H, Pharaoh P, Shah M, Whittemore AS, McGuire V, Sieh W, Sutphen R, Menon U, Gayther SA, Ramus SJ, Gentry-Maharaj A, Pearce CL, Wu AH, Pike MC, Risch HA, Jensen A. Ovarian Cancer Association Consortium (2013) Cigarette smoking and risk of ovarian cancer: a pooled analysis of 21 case-control studies. Cancer Causes Control 24(5): 989-1004.

Gram IT, Braaten T, Adami HO, Lund E, Weiderpass E (2008) Cigarette smoking and risk of borderline and invasive epithelial ovarian cancer. Int J Cancer 122(3): 647-652.

Gram IT, Lukanova A, Brill I, Braaten T, Lund E, Lundin E, Overvad K, Tjønneland A, Clavel-Chapelon F, Chabbert-Buffet N, Bamia C, Trichopoulou A, Zylis D, Masala G, Berrino F, Galasso R, Tumino R, Sacerdote C, Gavrilyuk O, Kristiansen S, Rodríguez L, Bonet C, Huerta JM, Barricarte A, Sánchez MJ, Dorronsoro M, Jirström K, Almquist M, Idahl A, Bueno-de-Mesquita HB, Braem M, Onland-Moret C, Tsilidis KK, Allen NE, Fedirko V, Riboli E, Kaaks R (2012) Cigarette smoking and risk of histological subtypes of epithelial ovarian cancer in the EPIC cohort study. Int J Cancer 130(9): 2204-2210.

International Agency for Research on Cancer (2012) IARC monographs on the evaluation of carcinogenic risks to humans. A Review of Human Carcinogens: Personal Habits and Indoor Combustions. International Agency for Research on Cancer: Lyon.

Jiao L, Zhu J, Hassan MM, Evans DB, Abbruzzese JL, Li D (2007) K-ras mutation and p16 and preproenkephalin promoter hypermethylation in plasma DNA of pancreatic cancer patients: in relation to cigarette smoking. Pancreas 34(1): 55-62.
Kurman RJ, Carcangiu ML, Herrington CS, Young RH (2014) WHO/IARC Classification of Tumours of Female Reproductive Organs, 4th edn. Lyon France: ISBN (EPUB) 978-92-832-4486-8.

Larsen IK, Smastuen M, Johannesen TB, Langmark F, Parkin DM, Bray F, Moller B (2009) Data quality at the Cancer Registry of Norway: an overview of comparability, completeness, validity and timeliness. Eur J Cancer 45(7): 1218-1231.

Licaj I, Lukic M, Jareid M, Lund E, Braaten T, Gram IT (2016) Epithelial ovarian cancer subtypes attributable to smoking in the Norwegian Women and Cancer Study, 2012. Cancer Med 5(4): 720-727.

Mayr D, Hirschmann A, Lohrs U, Diebold J (2006) KRAS and BRAF mutations in ovarian tumors: a comprehensive study of invasive carcinomas, borderline tumors and extraovarian implants. Gynecol Oncol 103(3): 883-887.

Newcomb PA, Storer BE, Marcus PM (1995) Cigarette smoking in relation to risk of large bowel cancer in women. Cancer Res 55(21): 4906-4909.

Næss O, Sogaard AJ, Arnesen E, Beckstrom AC, Bjertness E, Engeland A, Hjort PF, Holmen J, Magnus P, Njolstad I, Tell GS, Vatten L, Vollset SE, Aamodt G (2008) Cohort profile: cohort of Norway (CONOR). Int J Epidemiol 37(3): 481-485.

Parajuli R, Bjerkaas E, Tverdal A, Le ML, Weiderpass E, Gram IT (2014) Smoking increases rectal cancer risk to the same extent in women as in men: results from a Norwegian cohort study. BMC Cancer 14: 321.

Stocks T, Borena W, Strohmaier S, Bjorge T, Manjer J, Engeland A, Johansen D, Selmer R, Hallmans G, Rapp K, Concin H, Jonsson H, Ulmer H, Stattin P (2010) Cohort Profile: The Metabolic syndrome and Cancer project (Me-Can). Int J Epidemiol 39(3): 660-667.

Terry PD, Miller AB, Jones JG, Rohan TE (2003) Cigarette smoking and the risk of invasive epithelial ovarian cancer in a prospective cohort study. Eur J Cancer 39(8): 1157-1164.

Tworoger SS, Gertig DM, Gates MA, Hecht JL, Hankinson SE (2008) Caffeine, alcohol, smoking, and the risk of incident epithelial ovarian cancer. Cancer 112(5): 1169-1177.

Wentzensen N, Poole EM, Trabert B, White E, Arslan AA, Patel AV, Setiawan VW, Visvanathan K, Weiderpass E, Adami HO, Black A, Bernstein L, Brinton LA, Buring J, Butler LM, Chamosa S, Clendenen TV, Dossus L, Fortner R, Gapstur SM, Gaudet MM, Gram IT, Hartge P, Hoffman-Bolton J, Idahl A, Jones M, Kaaks R, Kirsh V, Koh WP, Lacey Jr JV, Lee IM, Lundin E, Merritt MA, Onland-Moret NC, Peters U, Poynter JN, Rinaldi S, Robien K, Rohan T, Sandler DP, Schairer C, Schouten LJ, Sjöholm LK, Sieri S, Swerdlow A, Tjonneland A, Travis R, Trichopoulou A, van den Brandt PA, Wilkens L, Wolk A, Yang HP, Zeleniuch-Jacquotte A, Tworoger SS (2016) Ovarian cancer risk factors by histologic subtype: an analysis from the Ovarian Cancer Cohort Consortium. J Clin Oncol 34(24): 2888-2898.

World Cancer Research Fund \& American Institute for Cancer Research (2014) Continuous Update Project Report. Food, Nutrition, Physical Activity, and the Prevention of Ovarian Cancer. Available at http:// www.wcrf.org/sites/default/files/Ovarian-Cancer-2014-Report.pdf.

Zenzes MT, Puy LA, Bielecki R (1998) Immunodetection of benzo[a]pyrene adducts in ovarian cells of women exposed to cigarette smoke. Mol Hum Reprod 4(2): 159-165.

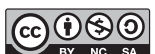

This work is licensed under the Creative Commons Attribution-Non-Commercial-Share Alike 4.0 International License. To view a copy of this license, visit http:// creativecommons.org/licenses/by-nc-sa/4.0/

(C) The Author(s) named above 2017

Supplementary Information accompanies this paper on British Journal of Cancer website (http://www.nature.com/bjc) 